\title{
MONITORAMENTO DOS CASOS DE ÓBITO EM UM AMBULATORIO ESPECIALIZADO EM IDOSOS
}

Joana D’arc Ricardo dos Santos, Edna Kasuko Sasajima, Andrea Aparecida da Fonseca Monteiro e Eduardo Canteiro Cruz

\section{INTRODUÇÃO}

O Atendimento ambulatorial requer instrumentos de rastreio que possam evidenciar as necessidades de acompanhamento e evolução dos casos atendidos, incluindo as causas dos casos de óbitos, este trabalho desenvolve um conjunto de ações, que visam ao esclarecimento da causa de óbito, além da detecção e investigação de qualquer agravo suspeito ou confirmado de doença de notificação compulsória atendido no Ambulatório, utilizando para isso as normas de vigilância epidemiológica nacionais, estaduais e municipais.

OBJETIVO: Classificar os casos de óbito, analisar causas e definir plano de ação voltados a melhoria da assistência em um ambulatório que atende pacientes unicamente maiores de 60 anos.

\section{DESENVOLVIMENTO}

Utilizamos como instrumento norteador o Relatório de Verificação de óbitos disponível no Programa Brasileiro de Segurança do PacientePBSP. Delegado para os enfermeiros das linhas de cuidados os levantamentos dos casos junto com o monitoramento dos pacientes e aos representantes da Diretoria Clinica e de Enfermagem analisar todo o percurso do paciente desde a admissão na unidade, conduta definida e causa óbito.

A análise foi realizada a partir dos casos de pacientes admitidos no ambulatório de geriatria inseridos no protocolo de classificação de risco de institucional que foi elaborado dividido em 3 eixos que sinalizam o risco de morte, divido em alto, médio e baixo risco.

\section{RESULTADOS}

Constituída a comissão de análise de óbitos em de janeiro de 2018, identificados até o mês de outubro 26 casos de óbitos classificados como: $56,15 \%$ justificados $17,78 \%$ inesperados e $26,07 \%$ não finalizados devido ausência de informações por insucesso no contato com os familiares e dados insuficientes para finalização do caso, entre os casos justificados 19,23\% eram casos oncológicos e 100\% estavam inseridos na linha de cuidado.
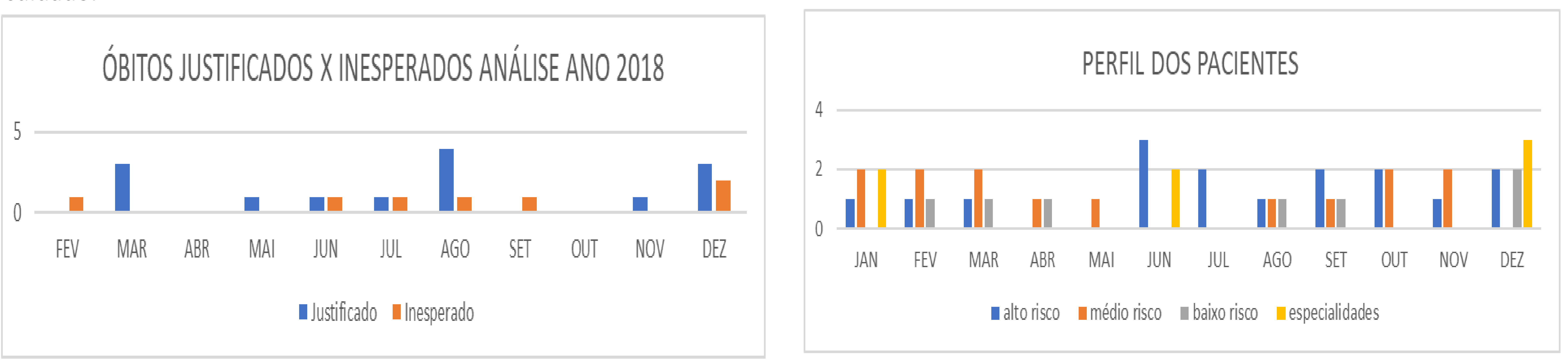

\section{CONCLUSÃO}

A análise dos casos proporcionou gerar um retrato das causas de óbitos dos pacientes em acompanhamento neste serviço. Os resultados vão ao encontro com o risco identificado na classificação de admissão do paciente, contribuindo para melhoria na coleta de dados, registro em prontuário e na gestão do cuidado.

\section{REFERÊNCIAS}

Desafio Zero Mortes Evitáveis 2020: Protocolo de Revisão e Análise de Óbitos - Programa Brasileiro de Segurança do Paciente Versão I. Agosto 2014. http://bvsms.saude.gov.br/bvs/saudelegis/gm/2006/prt1405 2906 2006.html 